\title{
Development of Adult-Generated Cell Connectivity with Excitatory and Inhibitory Cell Populations in the Hippocampus
}

\author{
Leonardo Restivo, ${ }^{1}$ Yosuke Niibori, ${ }^{1}$ Valentina Mercaldo, ${ }^{1}$ Sheena A. Josselyn, ${ }^{1,2,3,4}$ and Paul W. Frankland $d^{1,2,3,4}$ \\ ${ }^{1}$ Program in Neurosciences and Mental Health, The Hospital for Sick Children, Peter Gilgan Centre for Research and Learning, Toronto, Ontario, Canada, \\ M5G 0A4, and Departments of ${ }^{2}$ Psychology and ${ }^{3}$ Physiology and ${ }^{4}$ Institute of Medical Science, University of Toronto, Toronto, Ontario, Canada, M5S 1A8
}

\begin{abstract}
New neurons are generated continuously in the subgranular zone of the hippocampus and integrate into existing hippocampal circuits throughout adulthood. Although the addition of these new neurons may facilitate the formation of new memories, as they integrate, they provide additional excitatory drive to CA3 pyramidal neurons. During development, to maintain homeostasis, new neurons form preferential contacts with local inhibitory circuits. Using retroviral and transgenic approaches to label adult-generated granule cells, we first asked whether a comparable process occurs in the adult hippocampus in mice. Similar to development, we found that, during adulthood, new neurons form connections with inhibitory cells in the dentate gyrus, hilus, and CA3 regions as they integrate into hippocampal circuits. In particular, en passant bouton and filopodia connections with CA3 interneurons peak when adult-generated dentate granule cells (DGCs) are $\sim 4$ weeks of age, a time point when these cells are most excitable. Consistent with this, optical stimulation of 4-week-old (but not 6- or 8-week-old) adult-generated DGCs strongly activated CA3 interneurons. Finally, we found that CA3 interneurons were activated robustly during learning and that their activity was strongly coupled with activity of 4-week-old (but not older) adult-generated DGCs. These data indicate that, as adult-generated neurons integrate into hippocampal circuits, they transiently form strong anatomical, effective, and functional connections with local inhibitory circuits in CA3.
\end{abstract}

Key words: adult neurogenesis; CA3; dentate gyrus; mossy fibers; optogenetics

Significance Statement

New neurons are generated continuously in the subgranular zone of the hippocampus and integrate into existing hippocampal circuits throughout adulthood. Understanding how these cells integrate within well formed circuits will increase our knowledge about the basic principles governing circuit assembly in the adult hippocampus. This study uses a combined connectivity analysis (anatomical, functional, and effective) of the output connections of adult-born hippocampal cells to show that, as these cells integrate into hippocampal circuits, they transiently form strong connections with local inhibitory circuits. This transient increase of connectivity may represent an homeostatic process necessary to accommodate changes in the excitation/inhibition balance induced by the addition of these new excitatory cells to the preexisting excitatory hippocampal circuits.

\section{Introduction}

In the developing and adult hippocampus, new cells are generated in the subgranular zone (SGZ). The vast majority of these cells differentiate into neurons and migrate into the granule cell layer of the dentate gyrus (DG). They extend dendritic processes

\footnotetext{
Received Aug. 5, 2014; revised May 22, 2015; accepted June 20, 2015.

Author contributions: L.R., S.A.J., and P.W.F. designed research; L.R., Y.N., and V.M. performed research; L.R. and P.W.F. wrote the paper.

This work was supported by Natural Sciences and Engineering Research Council of Canada Grant RGPIN312434 and Canadian Institutes of Health Research Grants MOP86762 (P.W.F.) and MOP74650 (S.A.J.). L.R. was supported by the Hospital for Sick Children. We thank Chen Yan and Anne Wheeler for advice with the optogenetic experiments and for statistical analysis, respectively. We also thank Shaoyu Ge for providing the ChIEF construct and A. de Cristofaro, R. Braybon, and M. Yamamoto for technical assistance.
}

toward the molecular layer of the DG and mossy fiber axons toward targets in the hilus and CA3 region, eventually forming input and output synaptic connections (Zhao et al., 2006; Toni et al., 2007, 2008; Faulkner et al., 2008; Ide et al., 2008; Tronel et al., 2010; Deshpande et al., 2013; Sun et al., 2013). Although this sequence is invariable, integration of newly generated neurons into hippocampal circuits proceeds at a slower rate during adulthood than during development (Duan et al., 2008).

Correspondence should be addressed to Paul W. Frankland, Program in Neurosciences and Mental Health, The Hospital for Sick Children, Peter Gilgan Centre for Research and Learning, Toronto, Ontario, Canada, M5G OA4. E-mail: paul.frankland@sickkids.ca.

DOl:10.1523/JNEUROSCI.3238-14.2015

Copyright $\odot 2015$ the authors $\quad 0270-6474 / 15 / 3510600-13 \$ 15.00 / 0$ 
Because the great majority of cells generated in the SGZ differentiate into excitatory neurons (Zhao et al., 2008), these cells increase excitatory drive to target cells in CA3. There are several possible ways in which neural circuits might accommodate changes in balance between excitation and inhibition (Isaacson and Scanziani, 2011; Jinde et al., 2012). In particular, in the hippocampus, new neurons may form connections with local inhibitory circuits in the DG, hilus, or CA3 (Meltzer et al., 2005; Ikrar et al., 2013). For example, in the CA3 stratum-lucidum (CA3-sl), filopodial extensions from large mossy fiber terminals (LMTs) contact inhibitory interneurons (Acsády et al., 1998), and this may serve to maintain a balance between excitation and inhibition through feedforward inhibition (Meltzer et al., 2005; Danzer et al., 2010). Indeed, in the postnatal hippocampus, as new dentate granule cells (DGCs) integrate, there is a transient increase in filopodial extensions from LMTs (Wilke et al., 2013). Similarly, in the adult hippocampus, seizure induction promotes the formation of new filopodial extensions from LMTs (Danzer et al., 2010).

Accordingly, here we characterized the development of anatomical connections of newly generated DGCs in the adult hippocampus, focusing in particular on output connections with local inhibitory circuits. In particular, we asked whether changes in connectivity mirror changes in excitability of newborn cells. Because the excitability of adult-generated DGCs peaks between 4 and 6 weeks (Schmidt-Hieber et al., 2004; Ge et al., 2007; Mongiat et al., 2009; Gu et al., 2012; Marín-Burgin et al., 2012), we predicted that the formation of anatomical connections with local inhibitory circuits should follow a similar time course. We went on to ask whether optical stimulation of adult-generated DGCs activates inhibitory interneurons in the hippocampus and whether the activity of adult-generated DGCs and inhibitory interneurons is coupled during learning.

\section{Materials and Methods}

Mice

Wild-type mice. We used male mice derived from a cross between $129 \mathrm{~S} 6$ and C57BL/6N mice (Taconic Farms).

nestin-Cre $e^{E R T 2} \times R 26 R-Y F P$ mice. nestin-Cre ${ }^{\text {ERT2 }+}$ mice express a tamoxifen (TAM)-inducible form of Cre recombinase driven by a progenitor specific (nestin) promoter, as described previously (Imayoshi et al., 2008; Arruda-Carvalho et al., 2011). In these experiments, we used line 4 from Imayoshi et al. (2008) because recombination efficiency is highest in the SGZ of the hippocampus in this line (Imayoshi et al., 2008; Arruda-Carvalho et al., 2011). These mice were crossed with R26R-yellow fluorescent protein (YFP) reporter mice (Lagace et al., 2007). In this reporter line, YFP expression is under the control of the ubiquitous Rosa26 locus promoter, and expression of the YFP transgene is dependent on the Cre recombinase-mediated removal of a transcriptional STOP cassette. Accordingly, in male and female offspring from this cross, injection of TAM leads to expression of the YFP transgene only in nestinpositive $\left(\right.$ nestin $\left.{ }^{+}\right)$cells and their progeny. Both lines were maintained on a C57BL/6N background. Genotypes were determined by PCR analysis of tail DNA samples, as described previously (Lagace et al., 2007; ArrudaCarvalho et al., 2011).

Both wild-type (WT) and reporter lines were bred at The Hospital for Sick Children. Mice were weaned at $21 \mathrm{~d}$ and housed three to five mice per cage. They were maintained on a $12 \mathrm{~h}$ light/dark cycle (lights on at 7:00 A.M.) with access to food and water ad libitum. Behavioral procedures were conducted during the light phase of the cycle, blind to genotype of the mouse and according to protocols approved by the Animal Care Committee at The Hospital for Sick Children.

\section{Retroviral vectors}

To characterize the morphology of new DGCs, we used a replicationdeficient retroviral vector (based on the Moloney murine leukemia virus) in which a CAG promoter drives green fluorescent protein (GFP) expression (Tashiro et al., 2006; Stone et al., 2011). To stimulate new DGCs, we used a retroviral vector expressing a channelrhodopsin 2 chimera with a crossover site at loop E-F and Iisoleucine 170 mutated to valine (ChIEF) (Lin et al., 2009; Gu et al., 2012). Retroviruses were prepared in our laboratory by transfecting Plat-gp cells with plasmids containing an amphotropic envelope (vesicular stomatitis virus glycoprotein) and the transgenes. For CAG-GFP virus, Plat-E cells were then infected to generate a stable virus-producing cell line. The concentrated virus solution was obtained by ultra-speed centrifugation (average of $\sim 1.7 \times 10^{9}$ infection units/ml).

\section{Drugs}

TAM (Sigma) was dissolved in minimal ethanol and suspended in sunflower seed oil (Lagace et al., 2007). Reporter mice received five daily injections (180 mg/kg, i.p.), starting at postnatal day 42 (P42).

\section{Surgical procedures}

P10 and P42 WT mice were used for detailed morphological analyses of mossy fibers. Adult mice (P42) were anesthetized with chloral hydrate (400 mg/kg, i.p) and placed in a stereotaxic surgical frame (ASI Instruments). The scalp was incised and retracted, and drill holes in the skull were made above the hippocampi. Retrovirus expressing GFP was microinfused bilaterally into the DG $[0.5 \mu \mathrm{l}$ at a rate of $0.1 \mu \mathrm{l} / \mathrm{min}$; coordinates: anteroposterior (AP), $-2.2 \mathrm{~mm}$; mediolateral (ML), $1.8 \mathrm{~mm}$; dorsoventral (DV), $2.2 \mathrm{~mm}$ ) via a glass micropipette. The micropipette was left in place $5 \mathrm{~min}$ after the completion of the injection and then removed. The scalp wound was sealed with a stainless steel staple, and mice were treated with ketoprofen $(5 \mathrm{~kg} / \mathrm{mg}$, s.c.) postsurgically.

Infant mice (P10) were anesthetized with a lower dose of chloral hydrate $(200 \mathrm{mg} / \mathrm{kg}$, i.p.) and placed in a modified stereotaxic frame to accommodate their smaller skull. Retrovirus expressing GFP was microinfused bilaterally into the DG ( $0.2 \mu \mathrm{l}$ via a glass micropipette). After the microinfusion, the glass micropipette was removed immediately, and the wound was sutured. Mice were brought back to their home cage and left undisturbed until the start of the experiment.

For the optogenetic experiments, adult mice were microinfused unilaterally with retrovirus expressing ChIEF, using procedures identical to those described above. Five minutes after the completion of the microinfusion, the pipette was removed, the skull was gently scraped with a scalpel, and three anchoring screws were secured to the surface of the skull. One optical fiber [length, $2 \mathrm{~mm}$; diameter, $200 \mu \mathrm{m}$; 0.39 numerical aperture (NA); Thorlabs] was lowered above the DG (coordinates: AP, $-2.2 \mathrm{~mm}$; ML, $1.8 \mathrm{~mm}$; DV, $2.0 \mathrm{~mm}$ ), ipsilateral to the injection site. The optical fiber pedestal was fixed to the skull with dental cement.

\section{Optical stimulation}

Mice were transported to the experimental room in their home cage and received unilateral optical stimulation [two light ON epochs $(20 \mathrm{~Hz}, 9$ $\mathrm{mW}$, and $15 \mathrm{~ms}$ pulse width for $180 \mathrm{~s}$ ) separated by $3 \mathrm{~min}$ ]. Previous studies established that stimulation of DGCs at this frequency reliably activates CA3 pyramidal cells (Mori et al., 2004) and induces Fos expression (Liu et al., 2012). The implanted optrodes were tethered to a laser source (473 nm; Laserglow) through a split optic fiber (Precision Fiber Products) and controlled by a function generator (Agilent Technologies). One minute after the offset of the light, mice were disconnected from the laser source and returned to the vivarium. Ninety minutes after the completion of the optical stimulation, mice were anesthetized and perfused.

\section{Contextual fear conditioning apparatus and procedures}

Contextual fear conditioning occurred in test chambers $(31 \times 24 \times 21$ $\mathrm{cm}$; Med Associates) with shock-grid floors (bars $3.2 \mathrm{~mm}$ in diameter spaced $7.9 \mathrm{~mm}$ apart). The front, top, and back of the chamber were clear acrylic, and the sides were modular aluminum. During training, mice were placed in the chambers, and five footshocks $(0.7 \mathrm{~mA}, 2 \mathrm{~s}$ duration, 1 min apart) were delivered after 2 min. Mice were removed from the chambers 1 min after the last shock. During training, mouse behavior was monitored by video camera mounted on the ceiling of the cages, and the time spent freezing (i.e., absence of all but respiratory movement; 
Kim and Fanselow, 1992) was recorded using an automated scoring system (Freeze Frame software; Actimetrics).

\section{Fixation and tissue processing}

Mice were anesthetized with chloral hydrate and perfused intracardially with ice-cold $0.1 \mathrm{M}$ PBS, followed by $4 \%$ PFA. The brains were removed, postfixed in $4 \% \mathrm{PFA}$, and stored at $4^{\circ} \mathrm{C}$ until processed further. Fifty micrometer horizontal (for morphological analyses) or coronal (for behavioral and optogenetic experiments) sections were cut on a vibratome (VT1200s; Leica). Sections were washed in $0.1 \mathrm{M}$ PBS and incubated in blocking solution (2.5\% bovine serum albumin, $5 \%$ normal goat serum, or $5 \%$ normal donkey serum, $0.3 \%$ Triton X-100) for $2 \mathrm{~h}$. The following primary antibodies were used: goat polyclonal anti-GFP (1:500; Invitrogen), mouse monoclonal anti-parvalbumin (1:1000; Sigma), chicken polyclonal RFP (1:250; Millipore), mouse monoclonal anti-GAD67 (1: 1000; Millipore), rabbit polyclonal anti-c-fos (1:1000; Calbiochem), mouse monoclonal anti-NeuN (1:1000; Millipore), and mouse monoclonal anti-Bassoon (1:200; Enzo Life Sciences). The slices were incubated for $2 \mathrm{~h}$ at room temperature with the following secondary antibodies: Alexa Fluor 488 anti-rabbit, Alexa Fluor 488 anti-mouse, Alexa Fluor 633 anti-mouse, Alexa Fluor 568 anti-chicken, and Alexa Fluor 568 anti-rabbit (1:500; Invitrogen). The slices were washed in $0.1 \mathrm{M}$ PBS, counterstained with DAPI (1:1000; Sigma-Aldrich), mounted on slides, and coverslipped.

\section{Specific experimental procedures and analyses}

Morphological analyses. P42 mice were microinfused with retrovirus expressing GFP and then $2(n=4), 4(n=7), 6(n=6)$ or $8(n=7)$ weeks later were perfused. Additionally, a group of mice ("developmental"; $n=$ 7) received retroviral microinfusions at P10 and then were perfused 12 weeks later. Brains were sectioned horizontally to facilitate visualization of mossy fiber projections to CA3.

Detailed morphological analyses were performed on high-resolution stack images (objective, $63 \times / 1.4 \mathrm{NA}$; voxel size, $0.07 \times 0.07 \times 0.8 \mu \mathrm{m}$; image size, $1024 \times 1024$ pixels) acquired with a confocal microscope (dorsoventral range, -1.3 to $-2.5 \mathrm{~mm}$; LSM 710; Zeiss). The hilus and the CA3 region of the hippocampus were first identified using a lowmagnification objective $(20 \times / 0.8 \mathrm{NA})$. En passant boutons (defined as regular-shaped axonal swellings lacking filopodia protrusions) were identified in both the hilus and CA3 region. LMTs (defined as irregularshaped axonal swellings and, in most cases, filopodia) were identified in CA3. LMT and en passant bouton area were measured in the $z$ projection of confocal stacks by contour tracing with FIJI (Schindelin et al., 2012). Protrusions stemming from LMTs $(1 \mu \mathrm{m}<$ length $<20 \mu \mathrm{m}$; Acsády et al., 1998) with a bulbous head (cross-sectional area $<1 \mu \mathrm{m}^{2}$ ) were traced and counted as filopodia (Danzer et al., 2010). Filopodia number was expressed per LMT. Filopodia length and head size were measured in the $z$ projection of confocal stacks by contour tracing with FIJI. Threedimensional reconstructions of LMTs were obtained from highresolution image stacks (objective, $63 \times / 1.4 \mathrm{NA}$; voxel size, $0.02 \times 0.02 \times$ $0.46 \mu \mathrm{m}$; image size, $2048 \times 2048$ pixels $)$ processed with an inverse filtering deconvolution step (Image Pro; Media Cybernetics). These morphological measures were conducted on $\mathrm{GFP}^{+}$axons that were at least $200 \mu \mathrm{m}$ in length. To calculate the density of LMTs and en passant boutons, longer $\left(>500 \mathrm{GFP}^{+} \mu \mathrm{m}\right)$ segments were analyzed. LMT and bouton density was expressed as number per $100 \mu \mathrm{m}$.

The number of infected cells (per DG) was quantified in a subset of mice from each condition ( $n=4$ per group). The number of GFP ${ }^{+}$cells was counted manually on Z-stack projections of horizontal sections (objective, $10 \times / 0.3 \mathrm{NA}$; $Z$ stack, five slices; voxel size, $1.38 \times 1.38 \times 6.24$ $\mu \mathrm{m}$; image size: $1024 \times 2048$ pixels) and expressed as number of cells per $1000 \mu \mathrm{m}^{2}$.

These and all subsequent analyses were performed by an experimenter blind to the condition of the sample/animal.

Optogenetic experiments. WT mice were microinfused with retrovirus expressing ChIEF and then 4, 6, or 8 weeks later received optical stimulation in their home cage. Ninety minutes later, they were perfused, and immunohistochemistry for RFP, GAD67, and Fos was conducted on 50 $\mu \mathrm{m}$ coronal sections (to facilitate identification of optrode tips). Under low magnification (objective, $20 \times / 0.8 \mathrm{NA}$; Z stack, 10 slices; voxel size, $1.38 \times 1.38 \times 3 \mu \mathrm{m}$; image size: $\mathrm{DG}, 1024 \times 512$ pixels and CA3, $512 \times$ 512 pixels), the number of Fos ${ }^{+}$cells (expressed as number of cells per square millimeter) and Fos ${ }^{+} / \mathrm{GAD} 7^{+}$cells in DG and CA3 were quantified on both the illuminated and non-illuminated sides (dorsoventral range, -1.2 to $-2.5 \mathrm{~mm}$ ). Seven animals were excluded from the analysis because of either the absence of transgene expression or optical probe misplacement (four from the 4 week group, three from the 6 week group, and one from the 8 week group). After these exclusions, sample sizes were as follows: 4 weeks, $n=6$; 6 weeks, $n=7$; and 8 weeks, $n=7$.

Induction of Fos in excitatory and inhibitory cell populations after contextual fear conditioning. P42 YFP reporter mice $(n=23)$ were treated with TAM and then 4-6 weeks later (from the first day of TAM injections) were trained in contextual fear conditioning. Ninety minutes after contextual fear conditioning, mice were perfused, and Fos and GAD67 immunohistochemistry was conducted. To characterize activation in inhibitory cells, Fos expression was quantified in $\mathrm{GAD} 67^{+}$cells in the DG and CA3. To characterize training-induced activation in putative excitatory cells, Fos expression was quantified in GAD67-negative $\left(\right.$ GAD67 ${ }^{-}$) cells in the DG and CA3. Fos and GAD67 immunohistochemistry was conducted similarly on tissue from age-matched home-cage control mice $(n=19)$. Fold increase in activation was computed by normalizing counts in trained versus control mice for each region and cell population. Slices were taken from the dorsal hippocampus ( 1 in 4 sampling from -1 to $2.4 \mathrm{~mm}$ posterior to bregma), and sections from different groups were processed simultaneously. Fos expression was quantified from -1.2 to $-2.5 \mathrm{~mm}$ in the dorsoventral range. Note that this corresponds to the same dorsoventral range used for the morphological and optogenetic analyses.

Correlated Fos expression in different cell populations after contextual fear conditioning. In the same mice as above, we additionally conducted immunohistochemistry for YFP. Then, to assess functional connections among different hippocampal subpopulations, we evaluated to what degree Fos expression in adult-generated DGCs (i.e., Fos $^{+} / \mathrm{YFP}^{+}$cells) covaried with Fos expression in other cell populations (e.g., $\mathrm{Fos}^{+} /$ $\mathrm{GAD} 7^{+}$cells in CA3) by computing pairwise correlations (Pearson's $r$ ). To minimize type I errors, significant pairwise correlations were further probed using a permutation test (based on 9999 Monte Carlo resamplings). Functional connectivity may be inferred from within-subject variance (which is typically the case in human imaging studies) or between-subject variance (Horwitz et al., 1995; McIntosh, 1999). Because "activity" is inferred postmortem by changes in Fos expression (yielding single data point/mouse), here we computed covariance across mice to define functional connections between different neuronal subpopulations, as has been done previously (Soncrant et al., 1986; Fidalgo et al., 2012, 2014; Wheeler et al., 2013).

Images were acquired with a confocal microscope under low magnification (objective, $20 \times / 0.8 \mathrm{NA}$; Z stack, 16 slices; voxel size, $0.42 \times 0.42 \times$ $0.2 \mu \mathrm{m}$; image size: DG and hilus, $2048 \times 1024$ pixels and CA3, $1024 \times$ 1024 pixels). Fos expression was quantified in adult-generated DGCs (i.e., $\mathrm{YFP}^{+}$cells in the granule cell layer of the DG), as well as inhibitory (i.e., $\mathrm{GAD} 67^{+}$) and putative excitatory (i.e., $\mathrm{GAD} 67^{-}$) cells in the DG, hilus, and CA3. Numbers of double-labeled cells (e.g., Fos ${ }^{+} / \mathrm{GAD}{ }^{+}$in CA3) were normalized with respect to total Fos expression in the hippocampus for each mouse. In a subset of slices, immunohistochemistry for YFP and NeuN was conducted to assess maturation of YFP-tagged cells.

\section{Results}

\section{Retroviral labeling of DGCs}

Retroviruses infect dividing neural progenitors and their progeny (Tashiro et al., 2006). To characterize the development of connections, we microinfused a retrovirus expressing GFP into the DG of 42-d-old mice and conducted morphological analyses 2, 4, 6 , or 8 weeks after infection (Stone et al., 2011). To contrast the connectivity of adult-generated DGCs with DGCs born at an earlier developmental stage, an additional group of mice was microinfused at P10, and morphological analyses were conducted 

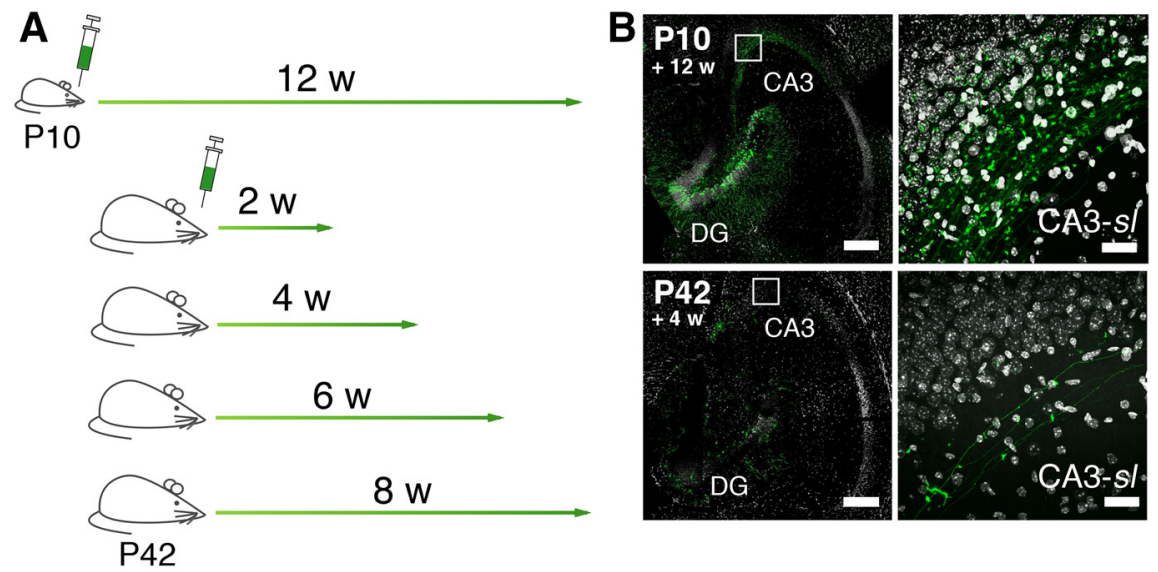

\section{C}

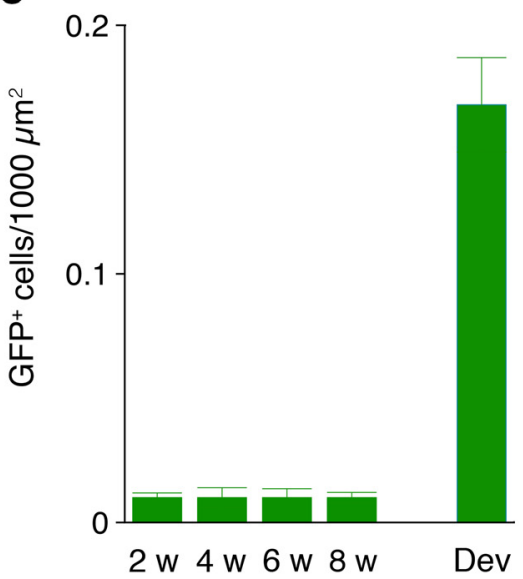

D

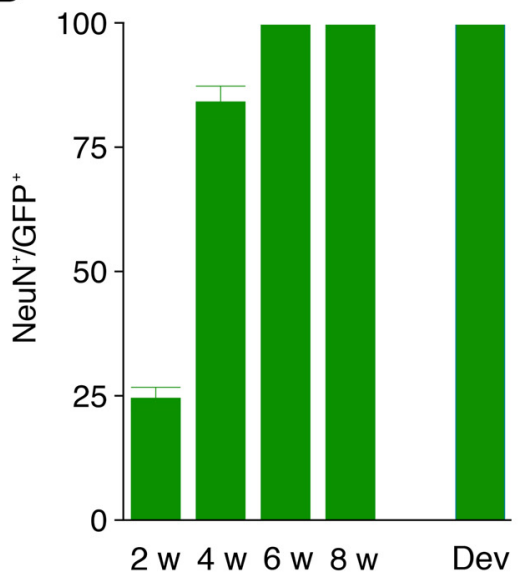

Figure 1. Retroviral labeling of newly generated DGCS. A, Scheme indicating timelines for retroviral injections and when the animals were killed. $\boldsymbol{B}$, Horizontal sections through the hippocampus in mice infected with the GFP-expressing retrovirus (green) at P10 and P42, respectively. Scale bar, $200 \mu \mathrm{m}$. Labeled DGCs extend their GFP ${ }^{+}$mossy fiber axons (inset) to the CA3-sl field. Scale bar, $50 \mu \mathrm{m}$. C, Quantification of the number of GFP ${ }^{+}$DGCs in mice microinjected at P10 (Dev) and P42 ( $2 \mathrm{w}, 4 \mathrm{w}, 6 \mathrm{w}, 8 \mathrm{w})$. D, Percentage of GFP ${ }^{+}$DGCs coexpressing the neuronal marker NeuN in mice microinjected at P10 (Dev) and P42 (2 w, 4 w, 6 w, 8 w).

12 weeks later (Fig. 1A). After these infusions, many $\mathrm{GFP}^{+}$DGCs were identified in the DG, and GFP-labeled mossy fibers were observed coursing toward the CA3 region (Fig. 1B). Consistent with age-dependent reductions in proliferation rates, more $\mathrm{GFP}^{+}$DGCs were observed after infection at P10 compared with P42 $\left(F_{(4,15)}=58.92 ; p<0.0001\right.$; Fig. $\left.1 C\right)$. Furthermore, coexpression of the mature neuronal marker NeuN increased as a function of neuron age, as expected $\left(F_{(4,23)}=320.3 ; p<0.0001\right.$; Fig. 1D).

\section{Formation of excitatory connections with CA3 pyramidal cells and interneurons}

GFP was robustly expressed after retroviral infection, allowing for detailed analysis of mossy fiber projections as they coursed through the hilus to CA3. As reported previously, three distinct types of mossy fiber presynaptic specializations were observed: (1) en passant boutons in the hilus and CA3-sl that innervate only inhibitory interneurons (Acsády et al., 1998; Fig. 2A,B); (2) LMTs that make excitatory contacts on spiny excrescences of CA3 pyramidal neurons (Acsády and Kali, 2007; Fig. 2B); and (3) filopodial-like extensions from LMTs that exclusively innervate inhibitory interneurons in CA3-sl (Acsády et al., 1998; Lawrence and McBain, 2003; Fig. 2B). Counterstaining the sections for parvalbumin confirmed that filopodia contact GABAergic in- terneurons (Fig. 2C; Ruediger et al., 2011). Furthermore, we found that Bassoon, a protein that is localized in active zones of presynaptic nerve terminals (tom Dieck et al., 1998), was expressed within the filopodial-like extensions (Fig. 2D). This is consistent with previous electron microscopy observations that LMTassociated filopodia in CA3 contain active zones (Acsády et al., 1998; Ruediger et al., 2011).

\section{Development of excitatory connections} with CA3 pyramidal cells

To characterize the development of presumed excitatory contacts onto CA3 pyramidal cells, we quantified both LMT size and density in the CA3-sl region (Fig. 3A). The cross-sectional area of LMTs increased as a function of post-infection delay $\left(F_{(4,25)}=85.63 ; p<0.0001\right)$, and, by 6-8 weeks after infection, GFP $^{+}$LMTs had equivalent cross-sectional areas compared with those from DGCs generated postnatally [least significant difference (LSD) post hoc tests, $p$ values $>0.05$; Fig. $3 B]$. We observed a similar pattern of changes in LMT density. Density increased as a function of post-infection delay $\left(F_{(4,20)}=4.70 ; p<0.01\right)$, and, by $6-8$ weeks after infection, the density of GFP ${ }^{+}$ LMTs was equivalent to those from DGCs born postnatally (LSD post hoc tests, $p>$ 0.05; Fig. 3C). These changes in LMT size and density match previous reports (Faulkner et al., 2008; Toni et al., 2008; Sun et al., 2013) and suggest that maturation of excitatory connections takes several weeks. Because larger LMTs usually contain more active zones (Pierce and Milner, 2001; Rollenhagen et al., 2007), this suggests that, as newly generated DGCs mature, they provide increasingly more powerful, high-fidelity input onto CA3 pyramidal cells (for review, see Rollenhagen and Lübke, 2010).

\section{Development of excitatory connections with CA3 interneurons}

To characterize the development of output connections with local inhibitory circuits in the hippocampus, we quantified changes in filopodia number on LMTs in CA3-sl and en passant boutons both in CA3-sl and the hilus. The number of filopodia/LMTs depended on the post-infection delay $\left(F_{(4,25)}=29.03 ; p<\right.$ 0.0001 ; Fig. $4 A-C)$. In particular, there was a pronounced spike in the number of $\mathrm{GFP}^{+}$filopodia/LMTs 4 weeks after infection (LSD post hoc tests: 4 weeks $>2,6$, and 8 weeks, $p$ values $<0.05$ ). However, by $6-8$ weeks after infection, filopodia density declined to levels observed in developmentally labeled cells (LSD post hoc tests, $p$ values $>0.05$ ). This transient peak was also observed when we estimated the total number $\left(F_{(4,25)}=25.66 ; p<\right.$ 0.0001; Fig. 4C, inset), rather than density, of filopodia (i.e., correcting for post-infection changes in LMT density; Fig. $3 C$ ). Although filopodia length was similar at all post-infection delays 
A

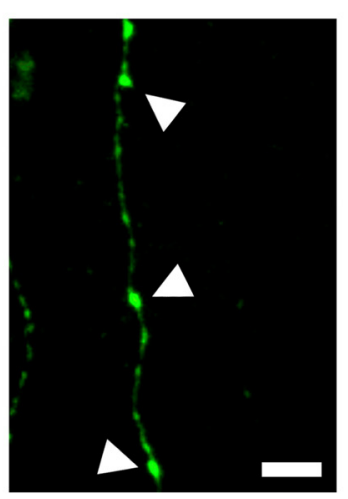

B

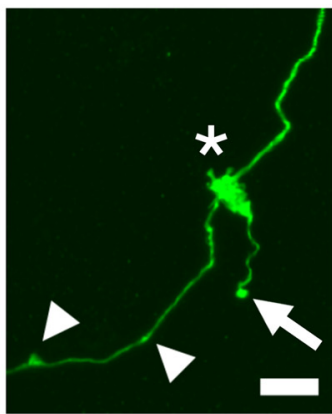

C

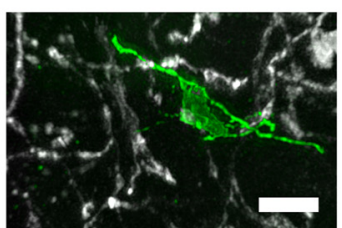

D

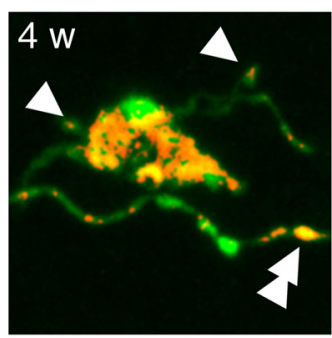

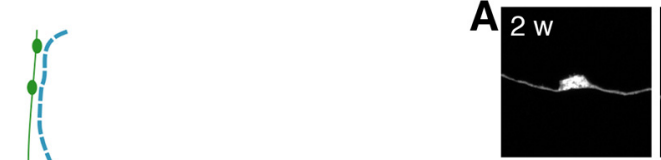

B

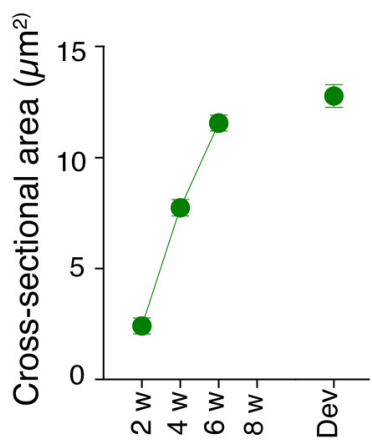

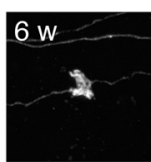

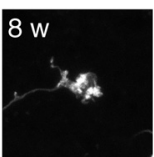

C
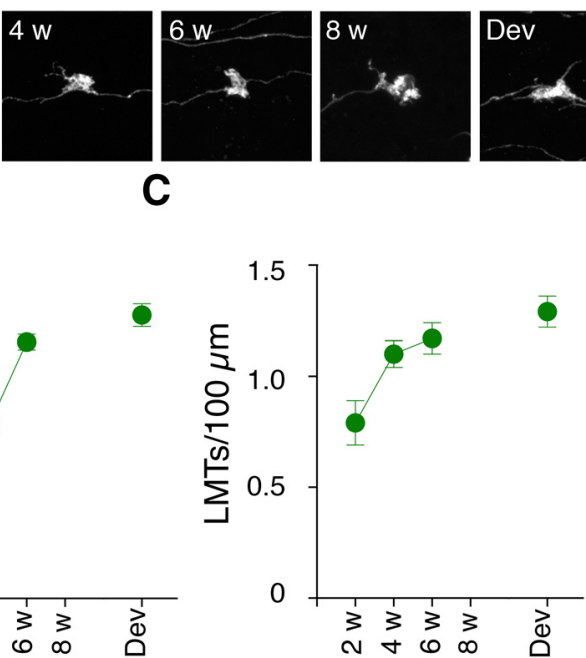

Figure 3. Maturation of connections with excitatory neurons. $A$, High-resolution images of LMTs associated with developmentally and adult-generated DGCs $(2,4,6$, and 8 weeks after infection). Scale bar, $5 \mu \mathrm{m}$. LMT cross-sectional area (B) and density (number of LMTs per 100 $\mu \mathrm{m} ; \boldsymbol{C})$ increases as a function of post-infection delay.

4 weeks after infection $\left(F_{(4,14)}=5.72 ; p<0.01\right.$; LSD post hoc tests: 4 weeks $>2$ weeks, 6 weeks and 8 weeks, $p$ s $<0.05$ ), with levels declining by $6-8$ weeks post-infection to those observed in developmentally labeled cells (LSD post hoc tests; $p s>0.05$ ). The size of en passant boutons in CA3-sl also varied as a function of post-infection delay with peak cross-sectional area at 4 weeks post-infection $\left(F_{4,12}=10.75 ; p<0.001\right.$; LSD post hoc tests: 4 weeks $>2,6$, and 8 weeks, $p$ values $<0.05$; Fig. $4 F$ ).

In contrast, en passant bouton density in the hilus did not vary with post-infection delay [but was generally lower compared with those observed in developmentally labeled cells $\left(F_{(4,15)}=\right.$ 3.15 ; $p<0.05$; Fig. $4 G$ )]. Similarly, en passant bouton area in the hilus did not vary with post-infection delay and did not differ from those observed in developmentally labeled cells $\left(F_{(4,23)}=\right.$ $0.27 ; p>0.05$; Fig. $4 H)$. This latter observation suggests that the transient peak in connectivity to local inhibitory circuits is limited to the CA3-sl region and does not occur in the hilus.

Development of effective connectivity with CA3 interneurons Our results indicate that, as adult-generated DGCs integrate into the hippocampus, they form anatomical connections with local inhibitory circuits via transient increases in the number of filopodia extending from LMTs and en passant boutons in CA3-sl. These results predict that stimulation of these adult-generated DGCs should activate CA3 inhibitory interneurons and that activation should be maximal when adult-generated DGCs are 4 weeks old. To address this question, we next microinjected retrovirus expressing the light-activated cation channel ChIEF unilaterally into the DG of adult mice (Lin et al., 2009; Gu et al., 2012). Then, at 4, 6, or 8 weeks later, we illuminated these cells via an optical fiber implanted above the DG while mice were in their home cage (Fig. $5 A, B$ ). The number of ChIEF-infected cells was similar across groups $\left(F_{(2,17)}=0.29 ; p>0.05\right)$, and illumination induced similar Fos expression across groups $\left(F_{(2,17)}=2.04 ; p>\right.$ 0.05 ; Fig. $5 C$ ). To assess the influence of light stimulation on the activity of different populations of inhibitory and excitatory cells in the DG, hilus, and CA3, we examined expression of the activity-regulated gene c-fos (Fig. $5 D-F$ ).

The pattern of Fos expression depended on the post-infection delay. Four weeks after retroviral infection, light stimulation ro-

$\left(F_{(4,24)}=1.60 ; p=0.21 ;\right.$ Fig. $4 D$, inset $)$, head size varied with post-infection delay $\left(F_{(4,18)}=11.59 ; p<0.001\right.$; Fig. $\left.4 D\right)$.

A comparable pattern of changes in density of en passant boutons was observed in CA3-sl (Fig. 4E). Similar to filopodia, there was a sharp increase in the number of $\mathrm{GFP}^{+}$en passant boutons 
A
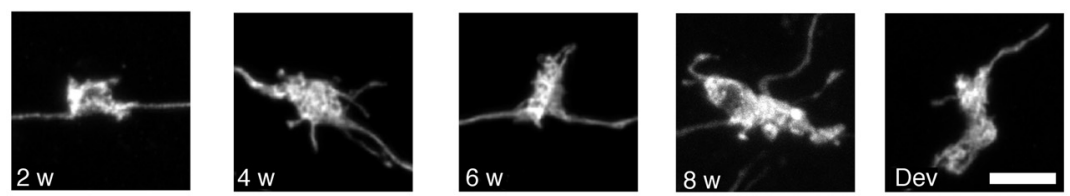

B
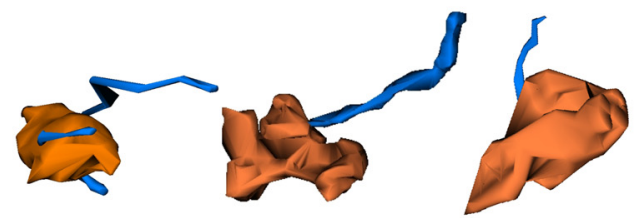

$8 w$

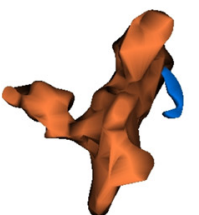

$2 w$

$4 \mathrm{w}$

$6 \mathrm{w}$

Dev
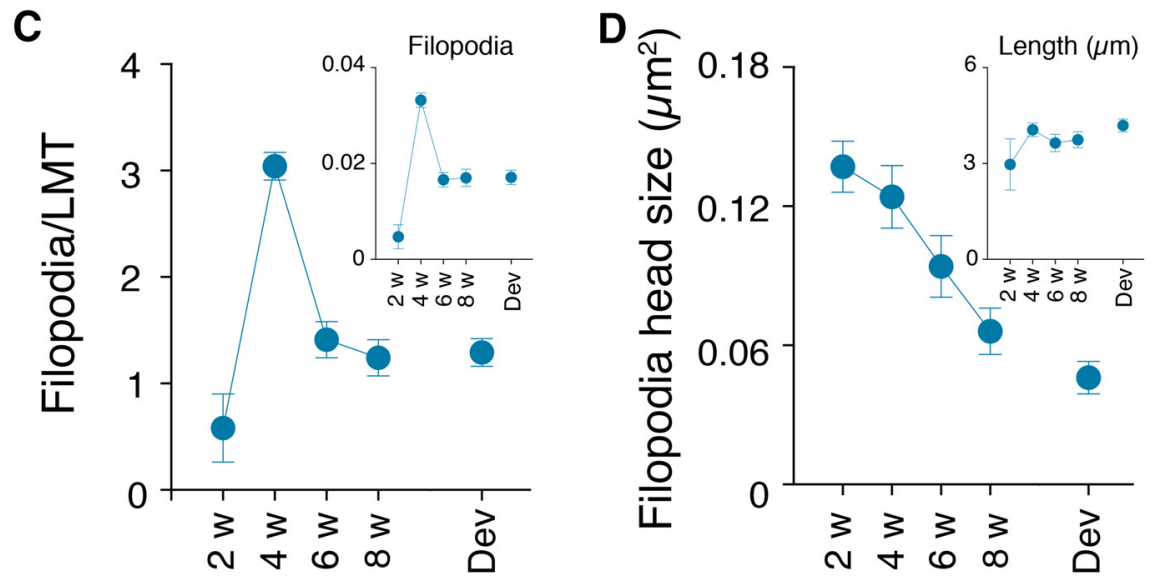

E
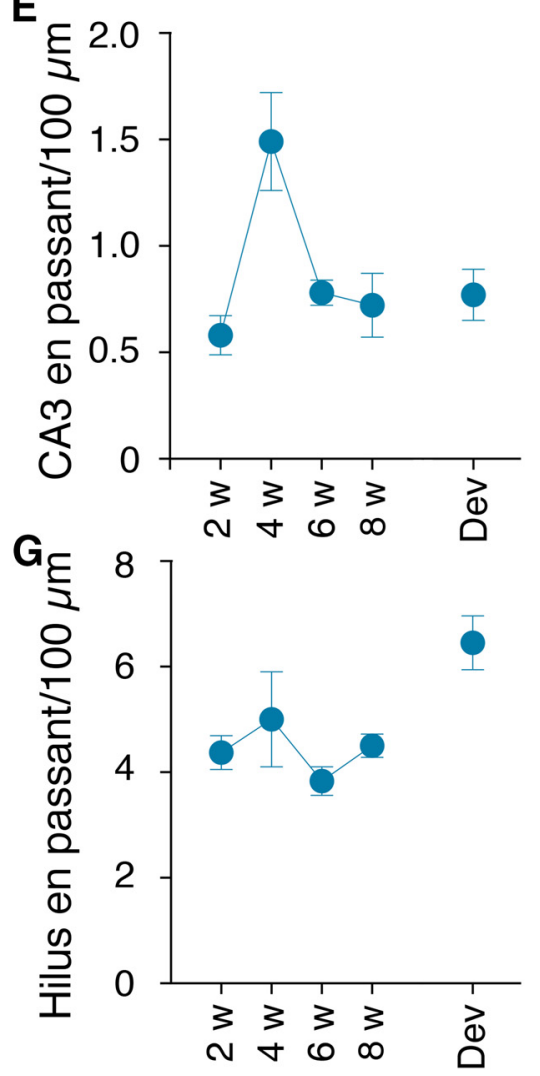

bustly increased Fos expression in inhibitory $\left(\mathrm{GAD} 7^{+}\right)$cells in the CA3 but not in the DG or hilus (Fig. $5 G-I$ ). In contrast, at 6-8 weeks after infection, the opposite pattern was observed. Light stimulation increased Fos expression in GAD67 ${ }^{+}$cells in the DG and hilus but not in CA3 (Fig. $5 G-I)$. A three-way ANOVA with cell age, side, and region as factors supported these conclusions. Most importantly, this analysis revealed a three-way interaction between these factors $\left(F_{(2,34)}=6.33 ; p<\right.$ 0.001 ), and post hoc tests indicated that artificial stimulation of 4-week-old adultgenerated DGCs strongly activated CA3 inhibitory interneurons (4 week ${ }_{\mathrm{ON}}>4$ week $_{\mathrm{OFF}} ; p<0.05$ ), and artificial stimulation of 6- to 8-week-old adult-generated DGCs activated inhibitory interneurons in DG $\left(6\right.$ week $_{\mathrm{ON}}>6$ week $_{\mathrm{OFF}}$ and 8 week $_{\mathrm{ON}}>8$ week $_{\mathrm{OFF}} ; p$ values $\left.<0.05\right)$ and hilus $\left(6\right.$ week $_{\mathrm{ON}}>6$ week $_{\mathrm{OFF}}$ and 8 week $_{\mathrm{ON}}>8$ week $_{\mathrm{OFF}} ; p$ values $\left.<0.05\right)$, respectively.

In the same mice, we found that light stimulation of 6- to 8-week-old adultgenerated DGCs elevated overall Fos levels in presumed excitatory cells (i.e., $\mathrm{GAD}^{-} 7^{-}$) in CA3. In contrast, light stimulation of 4-week-old adult-generated DGCs did not affect overall Fos levels in any hippocampal subregion (Fig. $5 J-L$ ). A three-way ANOVA with cell age, side, and region as factors supported these conclusions. We found a main effect of side $\left(F_{(1,17)}=11.39 ; p<0.001\right)$, indicating that Fos expression was generally elevated in the ON versus OFF condition. This analysis also revealed a significant threeway interaction between these factors $\left(F_{(2,34)}=3.53 ; p<0.05\right)$, and post hoc tests indicated that artificial stimulation of 6to 8-week-old adult-generated DGCs activated presumed excitatory neurons

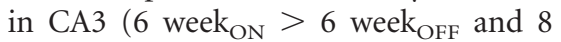
week $_{\mathrm{ON}}>8$ week $_{\mathrm{OFF}} ; p$ values $\left.<0.05\right)$.

Some limitations of this approach are worthwhile noting. Optical stimulation only activates small numbers of adultgenerated DGCs (because of incomplete retroviral infection and limits of light spread). Therefore, when populationlevel changes in Fos expression are observed after stimulation, this suggests that activity in the target population is modu-

length does not change as a function of post-infection delay. $\boldsymbol{E}$ En passant density in CA3 varies as a function of post-infection delay. $\boldsymbol{F}$, En passant area in CA3 varies as a function of postinfection delay. $\boldsymbol{G}$, En passant density in the hilus as a function of post-infection delay. $\boldsymbol{H}$, En passant area in hilus does not change as a function of post-infection delay.

Figure 4. Maturation of connections with inhibitory neurons. $A$, Representative images of LMTs associated with developmentally and adult-generated DGCs $(2,4,6$, and 8 weeks after infection). Scale bar, $5 \mu \mathrm{m}$. $\boldsymbol{B}$, Three-dimensional reconstructions of LMTs (orange) show the emergence of multiple filopodia (blue) from their surface. Four-week-old LMTs show the highest number of filopodia. Scale bar, $5 \mu \mathrm{m}$. C, The number of filopodia/LMTs varies as a function of post-infection delay. Inset, Number of filopodia normalized with respect to LMT density. D, Filopodia head size varies as a function of post-infection delay. Inset, Filopodia 
A

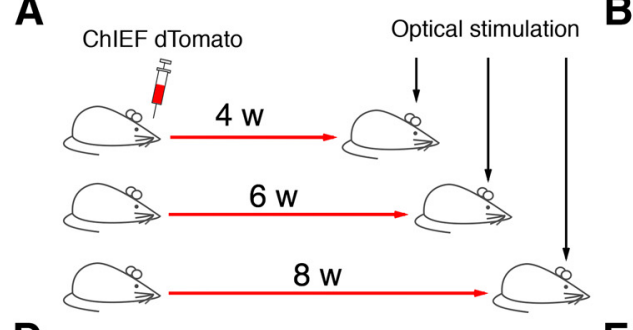

D
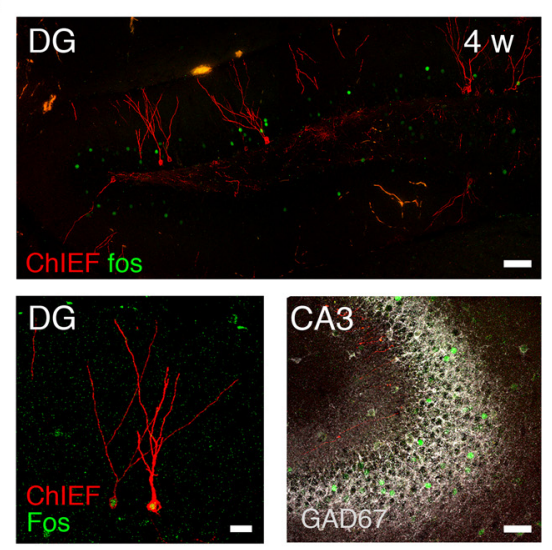

B

E
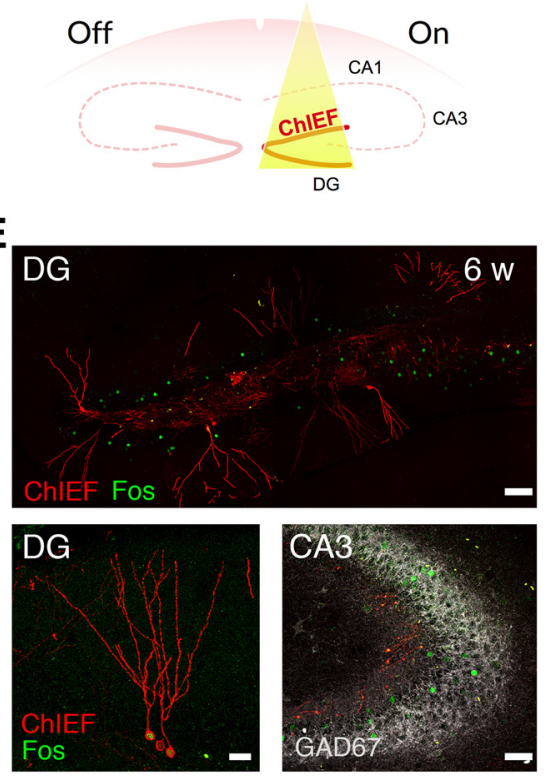

Hilus

H

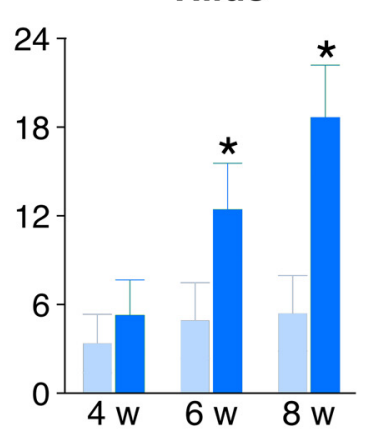

K

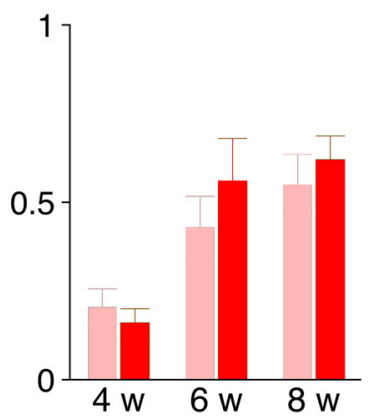

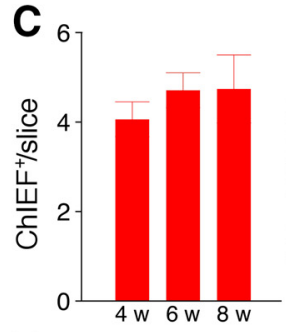

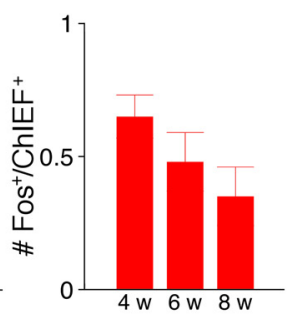

$\mathbf{F}$
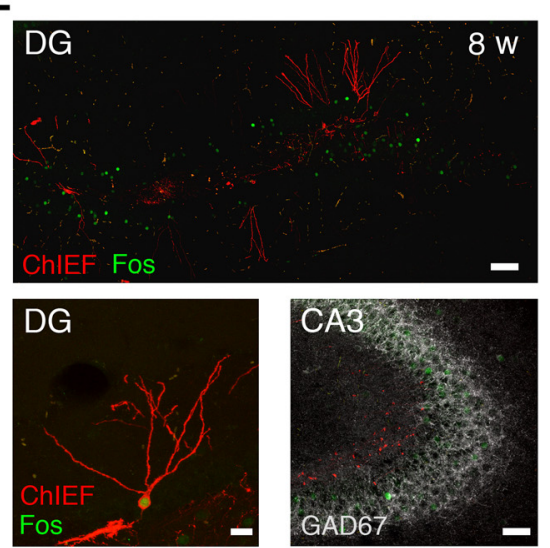

CA3

I

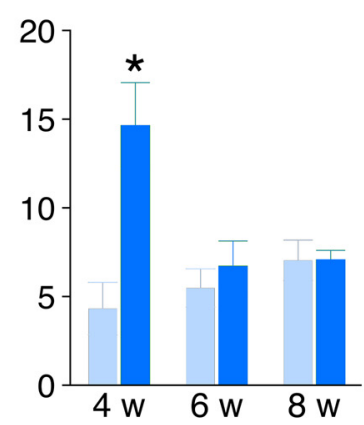

$\mathbf{L}$

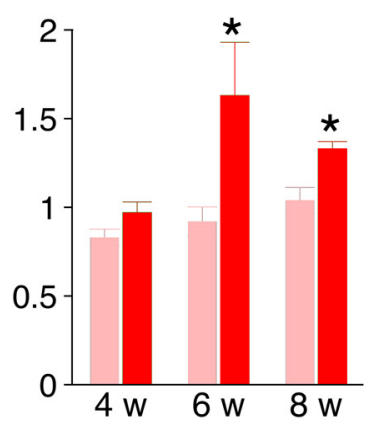

Figure 5. Optical stimulation in 4-week-old adult-generated DGCs activates CA3 inhibitory interneurons. $A$, ChIEF- $d$ Tomato-expressing retrovirus was microinjected unilaterally into the DG in adult WT mice. $\boldsymbol{B}$, Four to 8 weeks after retroviral infection, the mice received a unilateral intrahippocampal optical stimulation. C, Left, Number of ChIEF-infected DGCS per slice. Right, Number of ChlEF-infected DGCs expressing Fos after optical stimulation. Representative images of Fos expression (green) in presumed excitatory $\left(\mathrm{GAD}^{-} 7^{-}\right.$) and inhibitory $\left(\mathrm{GAD66} 7^{+}\right.$) cells after light stimulation of ChIEF (red)-infected DGCS $4(\boldsymbol{D}), 6(\boldsymbol{E})$, and $8(\boldsymbol{F})$ weeks after infection. Low-power scale bar, $100 \mu \mathrm{m}$; high-power scale bar, $50 \mu \mathrm{m}$. Percentage of GAD67 ${ }^{+}$cells expressing Fos after light stimulation $4-8$ weeks after infection in DG $(\boldsymbol{G})$, hilus $(\boldsymbol{H})$, and $C A 3(\boldsymbol{I})$. Number of $\mathrm{GAD} 67^{-}$cells expressing Fos after light stimulation $4-8$ weeks after infection in DG $(\boldsymbol{J})$, hilus $(\boldsymbol{K})$, and $C A 3$ (L). LSD post hoc tests, ${ }^{*} p<0.05$ compared with corresponding OFF condition.

lated reliably by activation of adult-generated DGCs. However, the absence of population-level changes in Fos expression does not necessarily imply the converse. Given the small numbers of DGCs targeted, population-level changes may fall below detectable levels. In this case, electrophysiological single-cell methods or calcium imaging-based approaches may be more sensitive.
Additionally, there was a strong (but nonsignificant) trend for light stimulation to induce greater levels of Fos expression in younger cells (see Fig. 7C). This is consistent with previous observations that younger cells are more excitable and might account for the observed group differences in interneuron activation. However, this is unlikely for two reasons. First, al- 

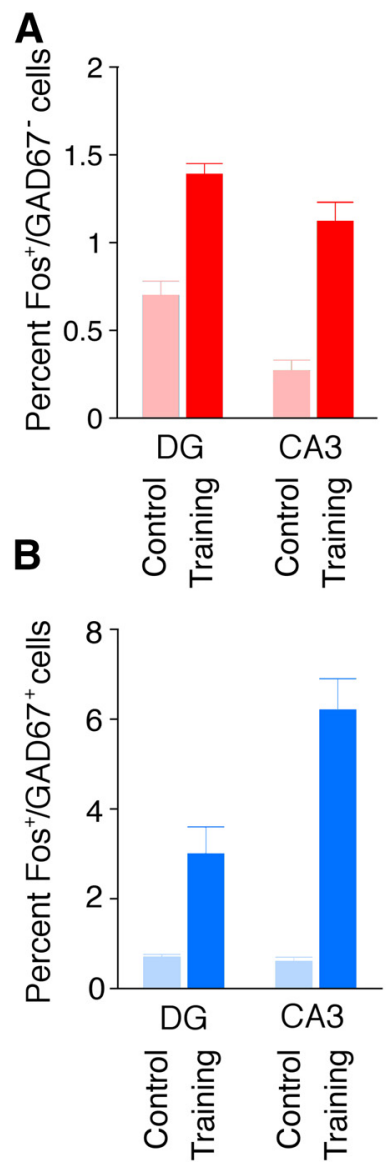

Figure 6. Contextual fear conditioning induces Fos in excitatory and inhibitory cells in the hippocampus. $A$, The number of Fos ${ }^{+}$ cells in DG and CA3 after contextual fear conditioning (training) versus home cage (control). $\boldsymbol{B}$, The percentage of GAD67 ${ }^{+}$cells expressing Fos in DG and CA3 after contextual fear conditioning (training) versus home cage (control). C, The fold increase in Fos expression in inhibitory and excitatory cells in DG and CA3 after conditioning (vs control).

though Fos expression in 4- and 8-week-old cells differed marginally after light stimulation $\left(t_{(11)}=2.04 ; p=0.061\right)$, there was no difference in Fos expression in 4- versus 6-week-old cells $\left(t_{(11)}\right.$ $=1.24 ; p=0.20)$. However, despite this lack of difference in activation, we found dissociable patterns of interneuron activation after light stimulation. That is, whereas stimulation of 4 -week-old cells induced Fos expression in interneurons in CA3 but not hilus or DG, stimulation of 6-week-old cells produced the opposite pattern: Fos was induced in interneurons in the hilus and DG but not in CA3. Second, activation of CA3 interneurons appears to be more sensitive to stimulation frequency than total number of fibers activated (Mori et al., 2004).

\section{Activation of CA3 interneurons during learning}

We next examined activation of different populations of inhibitory and excitatory cells after learning. To do this, we trained adult mice in contextual fear conditioning, a form of learning that engages the hippocampus (Kim and Fanselow, 1992), and quantified Fos expression. As expected, we found that training elevated Fos expression (compared with home cage controls) in excitatory cells in DG and CA3 (condition $\times$ region ANOVA: main effect of condition, $F_{(1,39)}=53.90 ; p<0.0001$; Fig. $6 A$ ). Similarly, we found that training elevated Fos expression in inhibitory cells in DG and CA3 (condition $\times$ region ANOVA: main effect of condition, $F_{(1,39)}=10.14 ; p<0.005$; Fig. $\left.6 B\right)$. Strikingly, the relative increase in Fos expression was greater in inhibitory compared with excitatory cells in the hippocampus (cell type $X$ region ANOVA: main effect of cell type, $F_{(1,44)}=33.92 ; p<0.0001$; main effect of region, $F_{(1,44)}=44.38 ; p<0.0001$; and cell type $\times$ region interaction, $F_{(1,44)}=$ 13.17; $p<0.0005$; Fig. $6 C$ ). In particular, training induced an $\sim 10$-fold increase in $\mathrm{Fos}^{+} / \mathrm{GAD} 7^{+}$cells in the CA3 region (LSD post hoc tests for $\mathrm{CA} 3_{\text {INHIB }}>\mathrm{DG}_{\mathrm{IN}^{-}}$ НІв, CA3 $3_{\mathrm{EXCIT}}, \mathrm{DG}_{\mathrm{EXCIT}}, p$ values $\left.<0.05\right)$.

Functional connectivity between adultgenerated DGCs and CA3 interneurons during learning

The above results indicate that CA3 inhibitory interneurons are activated robustly during learning and that adult-generated DGCs transiently form strong anatomical and effective connections with this population of cells as they integrate into adult hippocampal circuits. Together, these results predict that these two populations of cells should interact during hippocampusdependent learning. Therefore, using activity-dependent gene expression to identify recently active populations of neurons, we asked to what extent is activity coupled in these subpopulations during learning that engages the hippocampus (i.e., to what extent are they functionally connected; Friston et al., 1993; Pawela et al., 2008). Because increased anatomical and effective connectivity with local inhibitory circuits peaked at $\sim 4$ weeks, we predicted that any changes in functional connectivity would follow a similar temporal profile.

To label large numbers of adultgenerated DGCs, we used a cre/LoxP-based genetic approach in these experiments. Specifically, mice expressing a TAM-inducible cre recombinase driven by a progenitor-specific promoter (nestin$\mathrm{Cre}^{\mathrm{ERT2}}$ mice; Imayoshi et al., 2008; Arruda-Carvalho et al., 2011) were crossed with YFP reporter mice (Lagace et al., 2007). In adult offspring from this cross, TAM treatment leads to the permanent expression of YFP in progenitor cells and their progeny. Accordingly, P42 mice were treated with TAM and then, 4 or 6 weeks later, were trained in contextual fear conditioning (Fig. 7A). Ninety minutes after training, brains were removed and Fos expression was quantified in adult-generated DGCs (i.e., $\mathrm{YFP}^{+}$cells), as were different excitatory and inhibitory neuronal populations in the DG, hilus, and CA3 regions (Fig. 7B). Additional groups of reporter mice were treated identically but not trained (i.e., age-matched homecage controls). Although the genetic approach used here efficiently labels large numbers of adult-generated DGCs, temporal resolution is poorer compared with retroviral labeling strategies. Accordingly, we first quantified the proportion of YFP cells expressing NeuN 4 and 6 weeks after TAM. YFP ${ }^{+}$cells were likelier to coexpress the mature neuronal marker NeuN 6 weeks $(67.37 \pm 2.83 \%)$ compared with 4 weeks $(50.99 \pm 4.08 \%)$ after TAM $\left(t_{(13)}=3.24 ; p<0.01\right)$, suggesting that this labeled population contains a higher proportion of mature adult-generated DGCs, as predicted.

To assess functional connections among different hippocampal subpopulations, we evaluated to what degree Fos expression covaried in trained and control mice. Functional connectivity may be inferred from within-subject variance or between-subject 
A

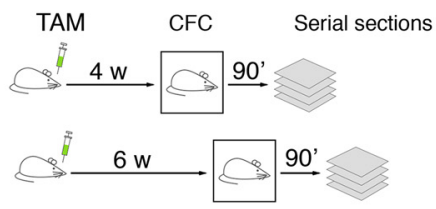

C
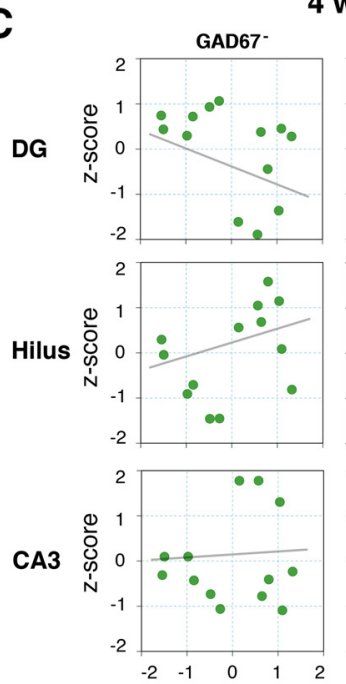

W
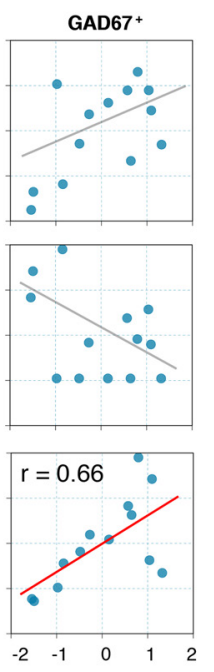

$\mathbf{F}$

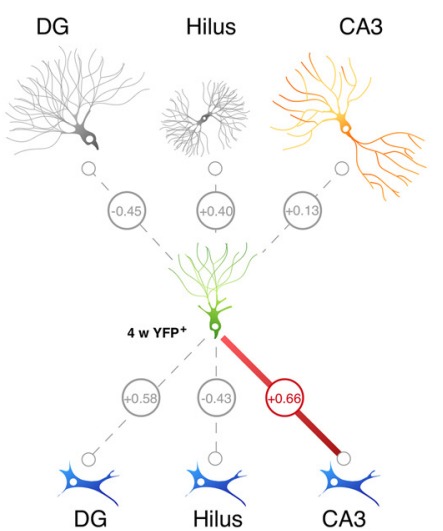

B

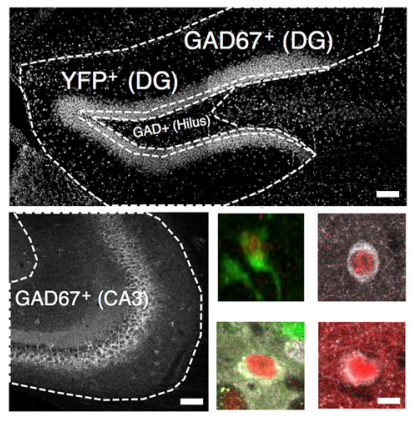

D
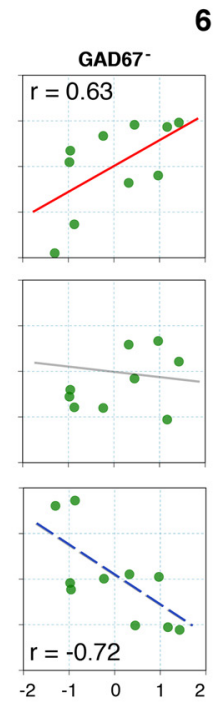

w
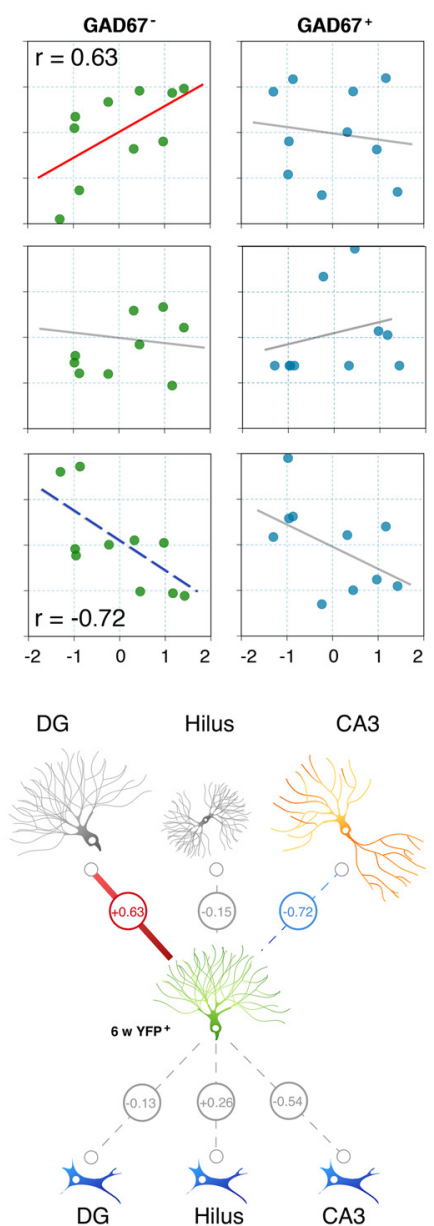

$\mathbf{E}$
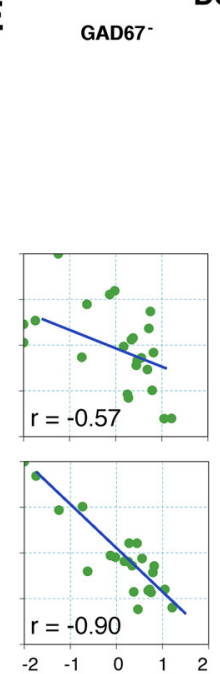

Dev
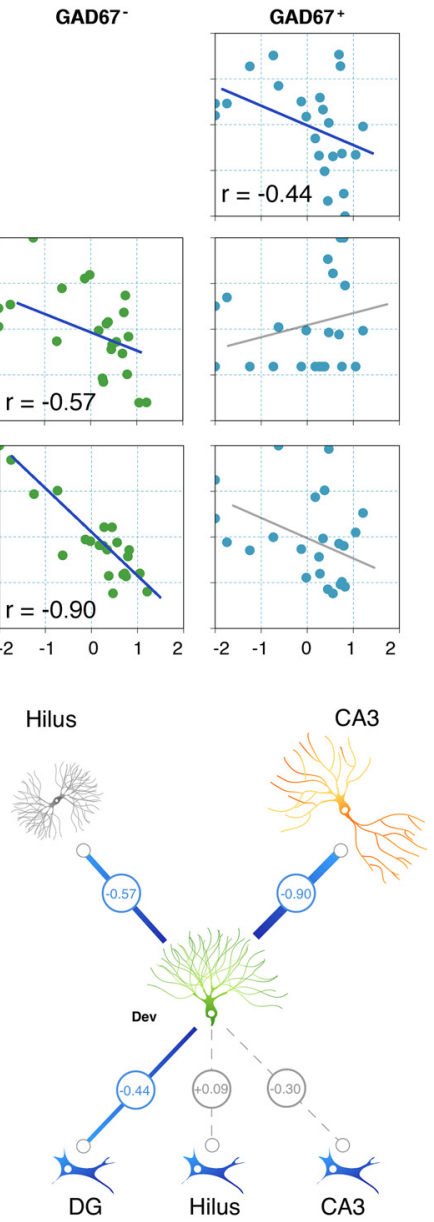

Figure 7. Correlated Fos expression in adult-generated DGCs and inhibitory interneurons in CA3 after learning. $\boldsymbol{A}$, nestin-cre ${ }^{\text {ERT2 }} \times$ RosaYFP mice received $5 \mathrm{~d}$ of TAM injections to induce expression of the reporter YFP in newly born neurons and were trained in contextual fear conditioning 4 or 6 weeks later. Ninety minutes after training, brains were removed and Fos immunohistochemistry was conducted. $\boldsymbol{B}$, Fos expression was measured in seven distinct hippocampal cell populations (adult-generated DGCs and inhibitory and excitatory cells in DG, hilus, and CA3). Scale bar, $100 \mu \mathrm{m}$. Adult-generated DGCs were defined as YFP ${ }^{+}$. Inhibitory cells were defined as $\mathrm{GAD} 67^{+}$and excitatory cells as GAD67 ${ }^{-}$. Examples of DG-YFP ${ }^{+}, \mathrm{DG}_{-\mathrm{GAD} 67}{ }^{+}$, hilus-GAD67 ${ }^{+}$, and CA3-GAD67 ${ }^{+}$cells are shown in the four bottom right panels. Scale bar, $10 \mu \mathrm{m}$. C, Scatter plots showing Fos expression in 4-week-old adult-generated DGCs versus excitatory and inhibitory cell populations in DG, hilus, and CA3. Fos expression in 4-week-old adult-generated DGCs was correlated with Fos expression in GAD67 ${ }^{+}$cells in the CA3. Fos in cell subpopulations is normalized with respect to total hippocampal Fos for each mouse and expressed as a $z$-score. D, Scatter plots showing Fos expression in 6-week-old adult-generated DGCs versus excitatory and inhibitory cell populations in DG, hilus, and CA3. Fos expression in 6-week-old adult-generated DGCs was correlated with Fos expression in GAD67 ${ }^{-}$cells in the DG and anticorrelated with Fos expression in GAD67 $^{-}$cells in the CA3 (although this correlation does not remain significant after permutation testing). E, Scatter plots showing Fos expression in developmentally generated DGCS (i.e., GAD67 ${ }^{-}$ cells in DG) versus excitatory and inhibitory cell populations in DG, hilus, and CA3. Fos expression in developmentally generated DGCs was anticorrelated correlated with Fos expression in GAD67 ${ }^{+}$ cells in DG and GAD67 ${ }^{-}$cells in hilus and CA3.F, Summaries of functional connections (inferred from correlated patterns of Fos expression across mice) for 4-week-old (4w YFP ${ }^{+}$) and 6-week-old $\left(6 \mathrm{w} \mathrm{YFP}^{+}\right)$adult-generated DGCs and for developmentally generated DGCs (Dev). Significant positive correlations are shown in red. Significant negative correlations are shown in blue. The dashed blue line indicates a negative correlation that did not survive permutation testing. Nonsignificant correlations are shown in gray.

variance (Mcintosh and Gonzalez-Lima, 1998). Because activity is inferred postmortem by changes in Fos expression (yielding single data point/mouse), here we computed covariance across mice to define functional connections between different neuro- nal subpopulations (Wheeler et al., 2013). After fear conditioning, we found that Fos expression in 4-week-old adult-generated DGCs was correlated reliably with Fos expression in inhibitory $\left(\mathrm{GAD} 7^{+}\right)$interneurons in the CA3 region $[r=0.66 ; p=0.01$ 
(after permutation testing)] but not with inhibitory interneurons in the DG $[r=0.58 ; p=0.13$ (after permutation testing) $]$ or hilus $(r=-0.43 ; p>0.05)$ regions (Fig. $7 C)$. In contrast, Fos expression in 4-week-old adult-generated DGCs was not correlated with Fos expression in GAD67 ${ }^{-}$cells (i.e., presumed excitatory cell populations $)$ in the DG $(r=-0.45 ; p>0.05)$, hilus $(r=0.40$; $p>0.05)$, or CA3 $(r=0.13 ; p>0.05)$ regions (Fig. $7 C)$.

We observed a different pattern for 6-week-old adultgenerated DGCs. Fos expression in 6-week-old adult-generated DGCs was not correlated with Fos expression in inhibitory interneuron populations in the DG $(r=-0.13 ; p>0.05)$, hilus $(r=0.26 ; p>0.05)$, or CA3 $(r=-0.54 ; p>0.05)$ regions (Fig. $7 D)$. However, Fos expression in 6-week-old adult-generated DGCs was correlated reliably with Fos expression in developmentally generated granule cells in the DG $[r=0.63 ; p<0.05$ (after permutation testing)]. Furthermore, Fos expression in 6-week-old adult-generated DGCs was anti-correlated with GAD67 $^{-}$cells (i.e., presumed excitatory cells) in CA3 $(r=$ $-0.72 ; p<0.05)$. However, this negative correlation was no longer reliable after permutation testing $(p=0.085$; Fig. $7 D)$.

Fos expression in developmentally generated DGCs (i.e., $\mathrm{GAD}^{-}$cells in the DG granule cell layer) was correlated with Fos expression in inhibitory interneuron populations in the DG $(r=-0.44 ; p>0.05)$ but not in the hilus $(r=0.09 ; p>0.05)$ or CA3 $(r=-0.30 ; p>0.05)$ regions (Fig. $7 E)$. Fos expression in developmentally generated DGCs was anti-correlated with GAD67 ${ }^{-}$cells (i.e., presumed excitatory cells) in the hilus $(r=$ $-0.57 ; p<0.05)$ and in CA3 $(r=-0.90 ; p<0.0001$; Fig. $7 E)$.

No correlations were significant for the control groups of mice (data not shown): 4 week control mice, $-0.34<r<0.30$ [all $p$ values $>0.05$ (before permutation testing)]; 6 week control mice, $-0.51<r<0.57$ [all $p$ values $>0.05$ (before permutation testing)].

These results indicate that changes in functional connectivity faithfully track changes in anatomical connectivity between adult-generated DGCs and inhibitory interneuron populations. First, the strongest anatomical and functional connections were observed between 4-week-old adult-generated DGCs and inhibitory interneurons in CA3. Second, similar to anatomical connections, strengthened functional connections between 4-week-old adult-generated DGCs and inhibitory interneurons were most pronounced in the CA3 region (Fig. $7 F$ ). Third, the activity of 6-week-old (but not 4-week-old) adult-generated DGCs was coupled with developmentally generated DGCs (Fig. 7F). Finally, the activity of 6-week-old DGCs (and developmentally generated DGCs) was correlated negatively with the activity of CA3 excitatory cells, a finding that is consistent with previous studies showing that activation of DGCs results in net inhibition of CA3 pyramidal cell firing (Bragin et al., 1995a,b; Penttonen et al., 1997). These contrasting patterns of anatomical and functional connectivity suggest that, as adult-generated DGCs mature, they begin to resemble their developmentally generated neighbors.

\section{Discussion}

Here we performed a series of experiments to characterize how adult-generated DGCs form connections with excitatory and inhibitory neurons as they integrate into hippocampal circuits. There are three primary results. First, using viral vector approaches to label newborn neurons, we found that, as newly generated DGCs integrate into hippocampal circuits, they form strong anatomical connections with CA3 interneurons via en passant boutons and filopodia-like extensions from LMTs. The number and density of these connections peaked when adult- generated DGCs were 4 weeks of age, when these cells begin to exhibit elevated excitability (Ge et al., 2007; Marín-Burgin et al., 2012). Second, optical stimulation of 4 -week-old adult-generated neurons robustly activated CA3 interneurons, suggesting strong effective connectivity between these two populations of cells. Third, CA3 interneurons were activated strongly after contextual fear conditioning, and this activity was correlated with the activity of 4-week-old adult-generated neurons, suggesting that these two subpopulations interact during learning. Although here we focused on the formation of output connections onto inhibitory interneurons in CA3, two recent studies (Bergami et al., 2015; Temprana et al., 2015) have identified complementary mechanisms that contribute to maintaining excitatory/inhibitory balance as adult-generated DGCs integrate into hippocampal circuits. First, as adult-generated DGCs mature beyond 4 weeks, they form connections with inhibitory interneurons in the DG and hilus that provide feedback inhibition onto DGCs (Temprana et al., 2015). Second, under environmental enrichment conditions, adult-generated DGCs are innervated transiently by inhibitory interneurons in CA1 and CA3 (Bergami et al., 2015).

Each DGC sends a single mossy fiber that projects through the hilus toward CA3 and contacts excitatory and inhibitory cells via distinct presynaptic specializations (Acsády et al., 1998). Although these presynaptic specializations develop similarly during development and during adulthood, the rate of maturation is much slower during adulthood (Overstreet-Wadiche et al., 2006; Faulkner et al., 2008; Toni et al., 2008). For instance, in our study, LMTs associated with adult-generated neurons appeared to be fully mature (in terms of size) by $\sim 6$ weeks of age. In contrast, during development, LMTs appear to be fully mature by $\sim 4$ weeks of age (i.e., the beginning of postnatal week 3; Faulkner et al., 2008). Similarly, whereas we found a sharp peak in number of filopodia at $\sim 4$ weeks of age in adult-generated neurons, this peak occurs earlier (at $\sim 2$ weeks of age) during development (Wilke et al., 2013).

The different methods we used here allowed us to describe the development of three different types of connectivity (Feldt et al., 2011). First, viral tracing revealed the development of anatomical connectivity (i.e., the physical connections between newly generated neurons and CA3 interneurons). Second, optogenetic stimulation combined with immediate early gene expression analysis revealed the development of effective connectivity (i.e., optical stimulations of newborn cells activated CA3 interneurons). Third, behavioral and immediate early gene expression analyses revealed the development of functional connectivity (i.e., the activity of adult-generated neurons and CA3 interneurons were correlated during learning). Although there is not always direct correspondence between these different forms of connectivity [Sporns, 2014; e.g., functional connections may be mediated by indirect anatomical connections (Honey et al., 2009)], here it is notable that they appear to emerge in parallel. That is, the number and density of presumed presynaptic connections onto inhibitory interneurons in CA3 peaked when adult-generated neurons reached $\sim 4$ weeks of age, and this time point corresponded with the age at which (1) optical stimulation of adult-generated DGCs most strongly activated CA3 interneurons and (2) activity of these two populations was most strongly correlated during learning.

However, patterns of connectivity were strikingly different in 4- versus 6- to 8-week-old adult-generated neurons. In particular, our analyses revealed strong interactions between adultgenerated cells and inhibitory interneurons in CA3 at 4 weeks of age. This pattern of strengthened connectivity with CA3 inhibi- 
tory microcircuits corresponds to a stage when new DGCs begin to display elevated intrinsic excitability, reduced GABAergic inhibition, and reduced threshold for spiking and activitydependent synaptic potentiation (Schmidt-Hieber et al., 2004; Espósito et al., 2005; Ge et al., 2007; Marín-Burgin et al., 2012). Because CA3 interneurons provide feedforward inhibition onto pyramidal CA3 cells (Lawrence and McBain, 2003), heightened connectivity with CA3 inhibitory microcircuits likely provides a mechanism for buffering additional excitatory drive from newborn cells.

In contrast, optical stimulation of 6- to 8-week-old adultgenerated DGCs did not induce Fos expression in CA3 inhibitory interneurons above baseline levels. A similar pattern emerged from the anatomical and functional connectivity analyses. By 6 weeks of age, the number and density of presumed contacts onto CA3 inhibitory interneurons resembled those observed in developmentally generated DGCs. Similarly, during learning, we found no correlation between Fos expression in 6-week-old adult-generated DGCs and CA3 interneurons, suggesting that they were not coactive. Instead, we found that the activity of 6-week-old adult-generated and developmentally generated DGCs were correlated strongly, suggesting that, by 6 weeks of age, adult-generated DGCs are acquiring a more mature cellular phenotype. This conclusion is consistent with several previous investigations of the morphological and physiological properties of adult-generated DGCs. For instance, as adult-generated DGCs mature, they exhibit similar intrinsic excitability, spiking threshold, and activity-dependent synaptic potentiation compared with developmentally generated DGCs (Laplagne et al., 2006; Ge et al., 2007; Mongiat et al., 2009; Gu et al., 2012). Although optical stimulation of 6- to 8-week-old adult-generated DGCs did not induce Fos expression in CA3 inhibitory interneurons, interestingly, we observed robust Fos expression in hilar and DG $\mathrm{GAD} 7^{+}$cells. This raises the intriguing possibility that feedforward inhibition (via activation of CA3 inhibitory interneurons) emerges sooner than feedback inhibition (via activation of inhibitory interneurons in the hilus and DG; Temprana et al., 2015).

Previous studies have identified maturation-dependent changes in the morphology and physiology of adult-generated DGCs (Espósito et al., 2005; Overstreet-Wadiche et al., 2006; Piatti et al., 2006; Zhao et al., 2006; Ge et al., 2007; Faulkner et al., 2008; Zhao et al., 2008; Mongiat et al., 2009; Gu et al., 2012; Kim et al., 2012; Marín-Burgin et al., 2012; Dieni et al., 2013; Sun et al., 2013). The current findings add to this pattern and additionally reveal that 4-week-old adult-generated DGCs have, at least partially, dissociable patterns of connectivity compared with more mature adult-generated DGCs. Therefore, these data underscore the idea that adult-generated neurons represent a heterogeneous pool of cells, with different aged cohorts of cells likely contributing to hippocampal information processing in distinct ways. In particular, we found that 4-week-old adult-generated DGCs interact strongly with CA3 inhibitory cells (and this interaction weakens by 6 weeks of age). Previous studies suggest that DGCCA3 inhibitory cell connections play critical roles in memory processing. For example, learning is associated with growth of new filopodial synapses, and the density of these connections correlates with memory precision (e.g., discrimination between similar contexts; Ruediger et al., 2011). These findings suggested that feedforward inhibition may be important for memory precision, and, consistent with this idea, genetic interventions that prevent filopodia growth (and therefore impair feedforward inhibition) are associated with memory imprecision and impaired population coding of similar contexts in CA3 (Ruediger et al., 2011).

Although the study by Ruediger et al. did not distinguish between adult-generated and mature DGCs, there is evidence that adult-generated DGCs play a similar role in memory precision. For instance, suppression of adult neurogenesis similarly impairs memory precision, assayed by contextual discrimination paradigms (Sahay et al., 2011; Kheirbek et al., 2012; Niibori et al., 2012; Tronel et al., 2012). In one study (Niibori et al., 2012), neurogenesis was suppressed genetically or pharmacologically for 4 weeks. The loss of cohorts of immature cells (i.e., 4 weeks old and younger) additionally impaired CA3 population coding of similar contexts (assessed using cellular compartment analysis of temporal activity by fluorescence in situ hybridization; Guzowski et al., 2005). This impaired population coding was reflected by an increase in the number of CA3 cells activated by two similar contexts. However, the increase in overlap did not appear to be driven by decreased segregation of cell populations responding to each of the contexts. Rather, increased overlap was associated with an expansion of the pool of cells activated by either context. This latter observation is consistent with the idea that the loss of immature adult-generated neurons impairs memory processing by reducing feedforward inhibition. According to this model, this loss of feedforward inhibition would decrease the activation threshold for CA3 cells, potentially leading to less efficient encoding and/or retrieval by reducing the fidelity of CA3 population codes. The finding that optogenetic inhibition of 4-week-old (but not 2- or 8-week-old) adult generated DGCs impairs retrieval of spatial memory (Gu et al., 2012) is consistent with this model.

\section{References}

Acsády L, Káli S (2007) Models, structure, function: the transformation of cortical signals in the dentate gyrus. Prog Brain Res 163:577-599. CrossRef Medline

Acsády L, Kamondi A, Sík A, Freund T, Buzsáki G (1998) GABAergic cells are the major postsynaptic targets of mossy fibers in the rat hippocampus. J Neurosci 18:3386-3403. Medline

Arruda-Carvalho M, Sakaguchi M, Akers KG, Josselyn SA, Frankland PW (2011) Posttraining ablation of adult-generated neurons degrades previously acquired memories. J Neurosci 31:15113-15127. CrossRef Medline

Bergami M, Masserdotti G, Temprana SG, Motori E, Eriksson TM, Göbel J, Yang SM, Conzelmann KK, Schinder AF, Götz M, Berninger B (2015) A critical period for experience-dependent remodeling of adult-born neuron connectivity. Neuron 85:710-717. CrossRef Medline

Bragin A, Jandó G, Nádasdy Z, Hetke J, Wise K, Buzsáki G (1995a) Gamma $(40-100 \mathrm{~Hz})$ oscillation in the hippocampus of the behaving rat. J Neurosci 15:47-60. Medline

Bragin A, Jandó G, Nádasdy Z, van Landeghem M, Buzsáki G (1995b) Dentate EEG spikes and associated interneuronal population bursts in the hippocampal hilar region of the rat. J Neurophysiol 73:1691-1705. Medline

Danzer SC, He X, Loepke AW, McNamara JO (2010) Structural plasticity of dentate granule cell mossy fibers during the development of limbic epilepsy. Hippocampus 20:113-124. CrossRef Medline

Deshpande A, Bergami M, Ghanem A, Conzelmann KK, Lepier A, Götz M, Berninger B (2013) Retrograde monosynaptic tracing reveals the temporal evolution of inputs onto new neurons in the adult dentate gyrus and olfactory bulb. Proc Natl Acad Sci U S A 110:E1152-E1161. CrossRef Medline

Dieni CV, Nietz AK, Panichi R, Wadiche JI, Overstreet-Wadiche L (2013) Distinct determinants of sparse activation during granule cell maturation. J Neurosci 33:19131-19142. CrossRef Medline

Duan X, Kang E, Liu CY, Ming GL, Song H (2008) Development of neural stem cell in the adult brain. Curr Opin Neurobiol 18:108-115. CrossRef Medline

Espósito MS, Piatti VC, Laplagne DA, Morgenstern NA, Ferrari CC, Pitossi FJ, Schinder AF (2005) Neuronal differentiation in the adult hippocam- 
pus recapitulates embryonic development. J Neurosci 25:10074-10086. CrossRef Medline

Faulkner RL, Jang MH, Liu XB, Duan X, Sailor KA, Kim JY, Ge S, Jones EG, Ming GL, Song H, Cheng HJ (2008) Development of hippocampal mossy fiber synaptic outputs by new neurons in the adult brain. Proc Natl Acad Sci U S A 105:14157-14162. CrossRef Medline

Feldt S, Bonifazi P, Cossart R (2011) Dissecting functional connectivity of neuronal microcircuits: experimental and theoretical insights. Trends Neurosci 34:225-236. CrossRef Medline

Fidalgo C, Conejo NM, González-Pardo H, Arias JL (2012) Functional interaction between the dorsal hippocampus and the striatum in visual discrimination learning. J Neurosci Res 90:715-720. CrossRef Medline

Fidalgo C, Conejo NM, González-Pardo H, Arias JL (2014) Dynamic functional brain networks involved in simple visual discrimination learning. Neurobiol Learn Mem 114C:165-170. CrossRef Medline

Friston KJ, Frith CD, Liddle PF, Frackowiak RS (1993) Functional connectivity: the principal-component analysis of large (PET) data sets. J Cereb Blood Flow Metab 13:5-14. CrossRef Medline

Ge S, Yang CH, Hsu KS, Ming GL, Song H (2007) A critical period for enhanced synaptic plasticity in newly generated neurons of the adult brain. Neuron 54:559-566. CrossRef Medline

Gu Y, Arruda-Carvalho M, Wang J, Janoschka SR, Josselyn SA, Frankland PW, Ge S (2012) Optical controlling reveals time-dependent roles for adult-born dentate granule cells. Nat Neurosci 15:1700-1706. CrossRef Medline

Guzowski JF, Timlin JA, Roysam B, McNaughton BL, Worley PF, Barnes CA (2005) Mapping behaviorally relevant neural circuits with immediateearly gene expression. Curr Opin Neurobiol 15:599-606. CrossRef Medline

Honey CJ, Sporns O, Cammoun L, Gigandet X, Thiran JP, Meuli R, Hagmann $P$ (2009) Predicting human resting-state functional connectivity from structural connectivity. Proc Natl Acad Sci U S A 106:2035-2040. CrossRef Medline

Horwitz B, McIntosh AR, Haxby JV, Grady CL (1995) Network analysis of brain cognitive function using metabolic and blood flow data. Behav Brain Res 66:187-193. CrossRef Medline

Ide Y, Fujiyama F, Okamoto-Furuta K, Tamamaki N, Kaneko T, Hisatsune T (2008) Rapid integration of young newborn dentate gyrus granule cells in the adult hippocampal circuitry. Eur J Neurosci 28:2381-2392. CrossRef Medline

Ikrar T, Guo N, He K, Besnard A, Levinson S, Hill A, Lee HK, Hen R, Xu X, Sahay A (2013) Adult neurogenesis modifies excitability of the dentate gyrus. Front Neural Circuits 7:204. CrossRef Medline

Imayoshi I, Sakamoto M, Ohtsuka T, Takao K, Miyakawa T, Yamaguchi M, Mori K, Ikeda T, Itohara S, Kageyama R (2008) Roles of continuous neurogenesis in the structural and functional integrity of the adult forebrain. Nat Neurosci 11:1153-1161. CrossRef Medline

Isaacson JS, Scanziani M (2011) How inhibition shapes cortical activity. Neuron 72:231-243. CrossRef Medline

Jinde S, Zsiros V, Jiang Z, Nakao K, Pickel J, Kohno K, Belforte JE, Nakazawa K (2012) Hilar mossy cell degeneration causes transient dentate granule cell hyperexcitability and impaired pattern separation. Neuron 76:11891200. CrossRef Medline

Kheirbek MA, Tannenholz L, Hen R (2012) NR2B-dependent plasticity of adult-born granule cells is necessary for context discrimination. J Neurosci 32:8696-8702. CrossRef Medline

Kim JJ, Fanselow MS (1992) Modality-specific retrograde amnesia of fear. Science 256:675-677. CrossRef Medline

Kim WR, Christian K, Ming GL, Song H (2012) Time-dependent involvement of adult-born dentate granule cells in behavior. Behav Brain Res 227:470-479. CrossRef Medline

Lagace DC, Whitman MC, Noonan MA, Ables JL, DeCarolis NA, Arguello AA, Donovan MH, Fischer SJ, Farnbauch LA, Beech RD, DiLeone RJ, Greer CA, Mandyam CD, Eisch AJ (2007) Dynamic contribution of nestin-expressing stem cells to adult neurogenesis. J Neurosci 27:1262312629. CrossRef Medline

Laplagne DA, Espósito MS, Piatti VC, Morgenstern NA, Zhao C, van Praag H, Gage FH, Schinder AF (2006) Functional convergence of neurons generated in the developing and adult hippocampus. PLoS Biol 4:e409. CrossRef Medline

Lawrence JJ, McBain CJ (2003) Interneuron diversity series: containing the detonation-feedforward inhibition in the CA3 hippocampus. Trends Neurosci 26:631-640. CrossRef Medline

Lin JY, Lin MZ, Steinbach P, Tsien RY (2009) Characterization of engineered channelrhodopsin variants with improved properties and kinetics. Biophys J 96:1803-1814. CrossRef Medline

Liu X, Ramirez S, Pang PT, Puryear CB, Govindarajan A, Deisseroth K, Tonegawa S (2012) Optogenetic stimulation of a hippocampal engram activates fear memory recall. Nature 484:381-385. CrossRef Medline

Marín-Burgin A, Mongiat LA, Pardi MB, Schinder AF (2012) Unique processing during a period of high excitation/inhibition balance in adultborn neurons. Science 335:1238-1242. CrossRef Medline

McIntosh AR (1999) Mapping cognition to the brain through neural interactions. Memory 7:523-548. CrossRef Medline

Mcintosh AR, Gonzalez-Lima F (1998) Large-scale functional connectivity in associative learning: interrelations of the rat auditory, visual, and limbic systems. J Neurophysiol 80:3148-3162. Medline

Meltzer LA, Yabaluri R, Deisseroth K (2005) A role for circuit homeostasis in adult neurogenesis. Trends Neurosci 28:653-660. CrossRef Medline

Mongiat LA, Espósito MS, Lombardi G, Schinder AF (2009) Reliable activation of immature neurons in the adult hippocampus. PLoS One 4:e5320. CrossRef Medline

Mori M, Abegg MH, Gähwiler BH, Gerber U (2004) A frequencydependent switch from inhibition to excitation in a hippocampal unitary circuit. Nature 431:453-456. CrossRef Medline

Niibori Y, Yu TS, Epp JR, Akers KG, Josselyn SA, Frankland PW (2012) Suppression of adult neurogenesis impairs population coding of similar contexts in hippocampal CA3 region. Nat Commun 3:1253. CrossRef Medline

Overstreet-Wadiche LS, Bensen AL, Westbrook GL (2006) Delayed development of adult-generated granule cells in dentate gyrus. J Neurosci 26 : 2326-2334. CrossRef Medline

Pawela CP, Biswal BB, Cho YR, Kao DS, Li R, Jones SR, Schulte ML, Matloub HS, Hudetz AG, Hyde JS (2008) Resting-state functional connectivity of the rat brain. Magn Reson Med 59:1021-1029. CrossRef Medline

Penttonen M, Kamondi A, Sik A, Acsády L, Buzsáki G (1997) Feed-forward and feed-back activation of the dentate gyrus in vivo during dentate spikes and sharp wave bursts. Hippocampus 7:437-450. CrossRef Medline

Piatti VC, Espósito MS, Schinder AF (2006) The timing of neuronal development in adult hippocampal neurogenesis. Neuroscientist 12:463-468. CrossRef Medline

Pierce JP, Milner TA (2001) Parallel increases in the synaptic and surface areas of mossy fiber terminals following seizure induction. Synapse 39: 249-256. CrossRef Medline

Rollenhagen A, Lübke JH (2010) The mossy fiber bouton: the "common" or the "unique" synapse? Front Synaptic Neurosci 2:2. CrossRef Medline

Rollenhagen A, Sätzler K, Rodríguez EP, Jonas P, Frotscher M, Lübke JH (2007) Structural determinants of transmission at large hippocampal mossy fiber synapses. J Neurosci 27:10434-10444. CrossRef Medline

Ruediger S, Vittori C, Bednarek E, Genoud C, Strata P, Sacchetti B, Caroni P (2011) Learning-related feedforward inhibitory connectivity growth required for memory precision. Nature 473:514-518. CrossRef Medline

Sahay A, Scobie KN, Hill AS, O'Carroll CM, Kheirbek MA, Burghardt NS, Fenton AA, Dranovsky A, Hen R (2011) Increasing adult hippocampal neurogenesis is sufficient to improve pattern separation. Nature 472:466470. CrossRef Medline

Schindelin J, Arganda-Carreras I, Frise E, Kaynig V, Longair M, Pietzsch T, Preibisch S, Rueden C, Saalfeld S, Schmid B, Tinevez JY, White DJ, Hartenstein V, Eliceiri K, Tomancak P, Cardona A (2012) Fiji: an opensource platform for biological-image analysis. Nat Methods 9:676-682. CrossRef Medline

Schmidt-Hieber C, Jonas P, Bischofberger J (2004) Enhanced synaptic plasticity in newly generated granule cells of the adult hippocampus. Nature 429:184-187. CrossRef Medline

Soncrant TT, Horwitz B, Holloway HW, Rapoport SI (1986) The pattern of functional coupling of brain regions in the awake rat. Brain Res 369:1-11. CrossRef Medline

Sporns O (2014) Contributions and challenges for network models in cognitive neuroscience. Nat Neurosci 17:652-660. CrossRef Medline

Stone SS, Teixeira CM, Devito LM, Zaslavsky K, Josselyn SA, Lozano AM, Frankland PW (2011) Stimulation of entorhinal cortex promotes adult neurogenesis and facilitates spatial memory. J Neurosci 31:13469-13484. CrossRef Medline 
Sun GJ, Sailor KA, Mahmood QA, Chavali N, Christian KM, Song H, Ming GL (2013) Seamless reconstruction of intact adult-born neurons by serial endblock imaging reveals complex axonal guidance and development in the adult hippocampus. J Neurosci 33:11400-11411. CrossRef Medline

Tashiro A, Zhao C, Gage FH (2006) Retrovirus-mediated single-cell gene knockout technique in adult newborn neurons in vivo. Nat Protoc 1:3049-3055. CrossRef Medline

Temprana SG, Mongiat LA, Yang SM, Trinchero MF, Alvarez DD, Kropff E, Giacomini D, Beltramone N, Lanuza GM, Schinder AF (2015) Delayed coupling to feedback inhibition during a critical period for the integration of adult-born granule cells. Neuron 85:116-130. CrossRef Medline

tom Dieck S, Sanmartí-Vila L, Langnaese K, Richter K, Kindler S, Soyke A, Wex H, Smalla KH, Kämpf U, Fränzer JT, Stumm M, Garner CC, Gundelfinger ED (1998) Bassoon, a novel zinc-finger CAG/glutaminerepeat protein selectively localized at the active zone of presynaptic nerve terminals. J Cell Biol 142:499-509. CrossRef Medline

Toni N, Teng EM, Bushong EA, Aimone JB, Zhao C, Consiglio A, van Praag H, Martone ME, Ellisman MH, Gage FH (2007) Synapse formation on neurons born in the adult hippocampus. Nat Neurosci 10:727-734. CrossRef Medline

Toni N, Laplagne DA, Zhao C, Lombardi G, Ribak CE, Gage FH, Schinder AF
(2008) Neurons born in the adult dentate gyrus form functional synapses with target cells. Nat Neurosci 11:901-907. CrossRef Medline

Tronel S, Fabre A, Charrier V, Oliet SH, Gage FH, Abrous DN (2010) Spatial learning sculpts the dendritic arbor of adult-born hippocampal neurons. Proc Natl Acad Sci U S A 107:7963-7968. CrossRef Medline

Tronel S, Belnoue L, Grosjean N, Revest JM, Piazza PV, Koehl M, Abrous DN (2012) Adult-born neurons are necessary for extended contextual discrimination. Hippocampus 22:292-298. CrossRef Medline

Wheeler AL, Teixeira CM, Wang AH, Xiong X, Kovacevic N, Lerch JP, McIntosh AR, Parkinson J, Frankland PW (2013) Identification of a functional connectome for long-term fear memory in mice. PLoS Comput Biol 9:e1002853. CrossRef Medline

Wilke SA, Antonios JK, Bushong EA, Badkoobehi A, Malek E, Hwang M, Terada M, Ellisman MH, Ghosh A (2013) Deconstructing complexity: serial block-face electron microscopic analysis of the hippocampal mossy fiber synapse. J Neurosci 33:507-522. CrossRef Medline

Zhao C, Teng EM, Summers RG Jr, Ming GL, Gage FH (2006) Distinct morphological stages of dentate granule neuron maturation in the adult mouse hippocampus. J Neurosci 26:3-11. CrossRef Medline

Zhao C, Deng W, Gage FH (2008) Mechanisms and functional implications of adult neurogenesis. Cell 132:645-660. CrossRef Medline 